\title{
The role of phototaxis in the initial swim bladder inflation of larval yellow perch (Perca flavescens)
}

\author{
Christopher R. Suchocki · Osvaldo J. Sepulveda-Villet
}

Received: 25 June 2018/Accepted: 15 February 2019/Published online: 5 March 2019

(C) The Author(s) 2019

\begin{abstract}
The yellow perch (Perca flavescens) is a high priority species for aquaculture, with strong demand in the USA. Unfortunately, numerous developmental problems during larval rearing prevent its commercial viability. Failed swim bladder inflation (SBI) has been reported in the culture of numerous physoclistous fish species and is a prominent problem in the culture of yellow perch. Initial SBI occurs within a short period of ontogeny, and missing this opportunity results in permanent malformation of the organ. Lighting cues appear to play a role in triggering the response of rising to the surface to swallow the air required for initial SBI in several fishes including yellow perch. Larval yellow perch are photopositive, and this phototactic response seems to co-occur with the window of opportunity for SBI. Thus, we examined the role of phototactic behavior and low-intensity, moonlight-like illumination in initial SBI in yellow perch. Lights were positioned below and above the water surface in larval culture tanks to see if the presence of nighttime illumination impacted SBI success, and if the phototactic behavior of yellow perch helps them find the water surface when inflating at night. The results of this study reveal that even very low-intensity nighttime light reduces the proportion of yellow perch larvae to initially inflate regardless of the direction of the light source. Also, on treatment with no nighttime illumination, higher than expected SBI was observed, and the culture conditions that produced this success should be examined when focusing on improving SBI in the future. This research suggests that the photopositive response of yellow perch is not involved in SBI success, and lighting could play a role in hindering the process.
\end{abstract}

Keywords Yellow perch $\cdot$ Larviculture $\cdot$ Swim bladder inflation $\cdot$ Phototaxis

\section{Introduction}

The yellow perch is a highly valued food and sport fish in the North American Great Lakes region. In the early 1990s, about $85 \%$ of recreational catches (by weight) in Lake Michigan were yellow perch, often by nearshore anglers (Francis et al. 1996). Unfortunately, soon after, the wild perch populations in Lake Michigan declined to historical lows (Marsden and Robillard 2004) and have not recovered to date. This decline has renewed interest in the improvement of yellow perch aquaculture as a food source, but advancements may increase the future possibilities of restoration activities for wild stock enhancement.

Presently, survivorship of cultured yellow perch larvae is extremely low, with swim bladder inflation (SBI) failure shown to be a significant impediment to its success (Craig 2000; Czesny et al. 2005; Hart et al. 2006;

C. R. Suchocki · O. J. Sepulveda-Villet ( $\varangle)$

Milwaukee School of Freshwater Sciences, University of Wisconsin, 600 E. Greenfield Ave., Milwaukee, WI 53207, USA

e-mail: sepulveo@uwm.edu 
Kestemont et al. 2015), as is for many other physoclistous species, such as yellowfin tuna Thunnus albacares (Partridge et al. 2011), burbot Lota (Rekecki et al. 2016), and the Eurasian perch Perca fluviatilis (Egloff 1996; Jacquemond 2004).

Yellow perch larvae without inflated swim bladders have been shown to capture prey less effectively and exhibit an abnormal swimming pattern (Czesny et al. 2005). Other fish species reported to suffer SBI failure exhibit difficulties with balance, locomotion, and regulating their position within the water column (Jacquemond 2004; Peruzzi et al. 2007; Prestinicola et al. 2014). Additionally, failed SBI regularly leads to malformations of the skeletal system often seen in the lower jaw and spine (Czesny et al. 2005; Kurata et al. 2014; Tsuji et al. 2016).

Methods to improve inflation deal mostly with abiotic environmental factors, such as water surface properties (Clayton and Summerfelt 2010), photoperiod modification (Partridge et al. 2011), and flow manipulation (Jentoft et al. 2006). Surface films and particles impede the inflation process and there has been significant improvement in SBI rates in tanks which have some method of removing surface substances either by skimming (Trotter et al. 2005), spraying (Clayton and Summerfelt 2010; Kestemont et al. 2015), or absorbing surface impediments (Hart et al. 2006; Tsuji et al. 2016). Yellow perch are positively phototactic until about $50 \mathrm{~mm} \mathrm{TL}$ and the shift in behavior is correlated with the development of the fish's digestive system, sensory organs, and later changes in the fish's diet and feeding behaviors (Hamza et al. 2015; Hart et al. 2006; Kamaszewski and Ostaszewska 2015; Manci 1983). In the closely related European perch, a continuous photoperiod has been shown to decrease the time before larval fish inflate their swim bladders when compared to a more natural photoperiod (Brüning et al. 2011). Thus, light and water surface condition seem to play a crucial role in inflation success (Woolley and Qin 2010).

The short, photopositive phase of larval yellow perch and the interval in which initial SBI occurs seem to correlate with each other. We hypothesize that wild larval yellow perch, because they are so small and such weak swimmers, have difficulty locating the surface of the water, and rely on their phototactic response, driven by the presence of moonlight, to locate the water's surface and inflate their swim bladders during the night. Thus, our objective is to examine the role of the phototactic response of larval yellow perch and lowlevel, nighttime illumination on their initial SBI, growth, and survival. Transferring this knowledge to culture practices would provide a simple solution to improve yellow perch survival at harvest by increasing SBI success.

\section{Methods}

Egg incubation

Yellow perch egg ribbons were obtained from captive stocks held at The University of Wisconsin-Milwaukee's School of Freshwater Sciences. All larvae for this experiment were sourced from the same egg ribbon which was spawned by hand, ensuring the gametes were from only one female and one male. Multiple egg ribbons were incubated, and the ribbon with the highest proportion of successfully developed eggs was used. The eggs were incubated in clear food-grade plastic containers holding $20 \mathrm{~L}$ of water and pinned to plastic racks to ensure proper water flow over the eggs. The ribbons were incubated using flow-through, dechlorinated water which began at a temperature of $10.5^{\circ} \mathrm{C}$ and increased to a temperature of $17.9^{\circ} \mathrm{C}$ over a period of 12 days.

The eggs were treated with a 10\% formalin solution (Dot Scientific Inc., Burton, MI, USA) as a fungicide. Formalin was dosed once daily, starting on the second day post-spawn. The volume of formalin used was $6 \mathrm{~mL}(300 \mathrm{ppm})$ for days 2 and 3, $12 \mathrm{~mL}$ (600 ppm) for days 4 through 9, and then reduced to $6 \mathrm{~mL}$ on day 10 (to avoid damaging the embryos as the chorion thins during development) and omitted in the final 2 days thereafter before hatching. By the end of the 11th day, numerous fish were seen hatching, and on the 12th day an acrylic rod was used to gently stir the large pieces of egg ribbon, such that the thinned chorions would rupture and assist the remaining unhatched fish to exit their egg. 
Larvae culture

After hatching, larvae were counted in beakers, and 250 fish were transferred into each of 12 respective experimental holding containers. These containers consisted of black HDPE buckets, with an internal standpipe surrounded by a $300 \mu \mathrm{m}$ screen, holding $6 \mathrm{~L}$ of water. Flow-through, dechlorinated water was dispensed at a rate of $8 \mathrm{~L} \mathrm{~h}^{-1}$ from a spray nozzle perpendicular to the water's surface. This spray assisted in breaking up and removing surface films that could hinder SBI of the larvae. The water temperature was raised from 17.9 to $20.0{ }^{\circ} \mathrm{C}$ over the first 2 days in the experimental tanks and remained at $20.0{ }^{\circ} \mathrm{C}$ for the 19 days of the experiment.

\section{Feeding}

The larvae were fed $100 \mathrm{~mL}$ of concentrated $\left(600\right.$ rotifer $\mathrm{mL}^{-1}$ ) saltwater rotifers (Brachionus plicatilis) twice daily at 9:00 am and at 3:00 pm. Artemia nauplii (36-h stage; Artemac USA LLC, Ogden, UT, USA) were added ( $\sim 20,000$ nauplii) twice daily along with the rotifers after the first 2 days for the remainder of the study. Rotifers and artemia were visually confirmed to be in the tank at multiple points in the day to verify the continuous presence of food.

\section{Lighting}

Two low-level, nighttime illumination treatments, one with nighttime light from above, and the other lit from below, and a control with no nighttime illumination were constructed using black 2-gallon buckets. Each treatment contained four replicates. If phototaxis is indeed used to help yellow perch larvae inflate their swim bladders, then the treatment with nighttime illumination from below the surface should result in failed SBI. These four replicates were separated by black, corrugated plastic sheets and draped in black plastic sheeting to block out all residual light. All lighting was controlled by automated electronic timers. All replicates in each of the three treatments were lit for $14 \mathrm{~h}$ during the day by a shared 50-lumen, $2700 \mathrm{~K} \mathrm{LED}$ driven at $12 \mathrm{~V}$, with a daytime light intensity of 80-100 lx at the water surface, followed by the experimental nighttime conditions for the remaining $10 \mathrm{~h}$. Nighttime light was created with a 24-lumen, $4000 \mathrm{~K} \mathrm{LED}$ driven at $7.5 \mathrm{~V}$, with a light intensity of less than $1.0 \mathrm{~lx}$ at the water surface. For the treatment in which nighttime illumination came from below the surface, the LEDs were encased in a clear resin enabling them to be submerged. The color, temperature, and intensity of the nighttime light are roughly analogous to those of natural moonlight at a full moon, reported to be $\sim 0.3 \mathrm{~lx}$ at the surface (Kyba et al. 2017).

\section{Mortalities and recovery}

Checks for mortalities occurred twice per day, before feedings. Mortalities were removed from the tank, counted, and preserved in $95 \%$ ethanol. A mortality curve was created by dividing the mean cumulative daily mortalities by the initially stocked 250 larvae and plotted against time. Recovery is used to describe the proportion of fish known to be recovered as a mortality, or larvae which survived to the end of the experiment. This percentage was calculated by dividing the sum of mortalities plus fish which survived to the end of the experiment by the 250 fish initially stocked in the treatments. The mean recovery percentages were then calculated from the three replicates for each treatment before being compared. Recovery was calculated to address any missing fish and to ensure these fish do not impart a bias on the final SBI proportions and other statistical analyses.

Sampling

From one of the four replicates in each treatment, a small sample of five random larvae was removed daily (as to not significantly deplete or skew survival patterns in the replicates) and euthanized with an overdose of buffered tricaine methanesulfonate (MS-222) (Western Chemical Inc., Ferndale, WA, USA) at a concentration of $300 \mathrm{mg} \mathrm{L}^{-1}$. Sampling was done to observe when the fish begin to inflate their swim bladders. These fish 
were imaged with a dissecting microscope to detect SBI (Barrows et al. 1993). After inspection and measurement, the carcasses were also preserved in $95 \%$ ethanol.

At the end of 19 days, when the opportunity for SBI was over, the experiment was ended, and all surviving fish were killed. Digital images of each fish were taken and their total length (TL) in mm was measured using previously calibrated software (Motic Images Plus 2.0). Inflation was clearly visible as a large bubble just above and in front of the stomach under the dissecting light microscope. Only fish in which the SBI success was clearly obvious were counted as successful inflates (see Fig. 3). These fish were measured to calculate a growth curve and the specific growth rates of each treatment to determine an effect of the treatments on the growth of the larvae.

Growth calculations

An exponential regression was employed to illustrate the differences in growth rates of sampled larval yellow perch TL over time $(t)$ between treatments, $\mathrm{TL}_{\mathrm{f}}$ being the mean total length of fish sampled on day 19 and $\mathrm{TL}_{0}$ being the mean TL of sampled fish the day the eggs hatched. The specific growth ratio (SGR) was calculated as follows:

$$
\mathrm{SGR}=100 \times\left[\left(\ln \mathrm{TL}_{\mathrm{f}}-\ln \mathrm{TL}_{0}\right) / t\right] .
$$

SGR traditionally uses weight to determine a growth rate of larval and juvenile fish since weight increases exponentially in young fish. In this situation, TL was used instead of weight because TL grew exponentially during our short sampling period, which is evidenced by the high coefficients of determination and thus high degree of fit of an exponential curve.

\section{Survivors}

After 19 days the experiment was ended, and all surviving fish left were euthanized. The number of fish left at the end of the experiment was divided by the initial 250 larvae stocked. Upon euthanasia, the larvae were imaged, TL was measured, and SBI was visually confirmed. The data were recorded.

Statistical analysis

An effect of the treatments on the means of recovery, survival, final TL, and the proportion of fish that successfully inflated their swim bladders was examined using a one-way analysis of variance (ANOVA). Differences at the 5\% level were considered significant. In the single case in which a significant difference was found, pairwise comparisons of percent abundance between treatments were made using Tukey's honest significance test.

To transform the proportions of fish with successfully inflated swim bladders into a normal distribution, the values were logit transformed as below (Warton and Hui 2011):

$$
\operatorname{logit}(p)=\ln \left(\frac{p}{(1-p)}\right)
$$

where ' $p$ ' is the mean proportion of larvae with successfully inflated swim bladders within a replicate.

Analysis of covariance (ANCOVA) was used to compare the regressions using TL as the dependent variable, day post-hatch (dph) as the covariate, and the different nighttime light treatments as the group variable. 


\section{Results}

Survival and recovery

Mean percent recovery for each of the treatments in which the low-level nighttime illumination source was above the water surface ("Above"), below the water surface ("Below"), and completely absent/dark ("Control") was $87.7 \pm 4.3 \%, 78.9 \pm 9.9 \%$, and $79.1 \pm 10.0 \%$, respectively (Table 1). ANOVA indicates that there was no significant difference in the percent recovery between the treatments $\left(F_{2,6}=1.161\right.$, $p=0.375)$.

After 19 days post-hatch, yellow perch larvae survival in individual tanks ranged from 17.6 to 65.2\%. Mean survivorship was highest in the "Control" treatment $(59.6 \pm 3.12 \%)$, followed by the "Below" treatment $(54.8 \pm 7.33 \%)$, and "Above" (46.4 $\pm 25.33 \%)$ (Table 1). There was no significant difference of survivorship between treatments when tested via ANOVA $\left(F_{2,6}=0.599, p=0.579\right)$.

Cumulative mortality remained below $5 \%$ until the $10 \mathrm{dph}$ in all treatments. $8 \mathrm{dph}$ there was a notable increase in mortality seen in the "Control" treatment. During this period, mortality remained low in the "Above" and "Below" treatments. The "Above" and "Below" treatments experienced a spike in mortality from 13 to $15 \mathrm{dph}$ which was not seen in the "Control" treatment, although in the "Control" mortality grew consistently over this time. Final cumulative mortality was 19.3, 24.1, and 19.5\% for the "Above", "Below", and "Control" treatments, respectively (Fig. 1).

Final length and growth

The mean TL and standard deviation of all surviving fish at the end of the experiment was $8.26 \pm 0.73 \mathrm{~mm}$, $8.33 \pm 0.84 \mathrm{~mm}$, and $9.07 \pm 0.83 \mathrm{~mm}$ for the "Above", "Below", and "Control" nighttime illumination treatments, respectively (Table 1$)$; this difference was found to not be significant $\left(F_{2,6}=3.10, p=0.12\right)$. The fish that were sampled daily were also measured (Fig. 2). An exponential regression fit the growth data of sampled fish best with coefficients of determination of $0.86,0.93$, and 0.93 for the "Above", "Below", and "Control" treatments, respectively. Specific growth rate (SGR) over $19 \mathrm{dph}$ was $1.54 \pm \% \mathrm{day}^{-1}, 1.78 \%$ day $^{-1}$, and $2.16 \%$ day $^{-1}$ for the "Above", "Below", and "Control" nighttime illumination treatments, respectively (Table 1 ).

There is no significant effect of the nighttime light treatments on the TL of the larvae after controlling for time $\left(F_{2,265}=0.457, p=0.634\right)$. The slope and intercepts are determined to be indistinguishable, and thus the growth rates between treatments are considered to be the same.

Swim bladder inflation

An example of an unsuccessfully inflated larva versus a successfully inflated larva can be seen in Fig. 3. The mean proportion of surviving yellow perch larvae with successful SBI was highest in the "Control" treatment where no nighttime illumination was present, $92.84 \pm 4.47 \%$. The treatments with low-level, nighttime illumination had SBI success fractions of $79.89 \pm 11.82 \%$ and $45.99 \pm 16.85 \%$ for the "Above" and

Table 1 Effects of low-level nighttime light of different source locations (above and below the water's surface) on survival, recovery, growth, and swim bladder inflation of yellow perch (Perca flavescens) until $19 \mathrm{dph}$

\begin{tabular}{llllll}
\hline Treatment & $\begin{array}{l}\text { Survival } \\
(\%)\end{array}$ & $\begin{array}{l}\text { Recovery } \\
(\%)\end{array}$ & $\begin{array}{l}\text { Final total } \\
\text { length }(\mathrm{mm})\end{array}$ & $\begin{array}{l}\text { Specific Growth } \\
\text { Rate }\left(\% \text { day }^{-1}\right)\end{array}$ & $\begin{array}{l}\text { Swim bladder } \\
\text { inflation }(\%)\end{array}$ \\
\hline "Above" & $46.4 \pm 25.3$ & $87.7 \pm 4.3$ & $8.261 \pm 0.727$ & 1.54 & $79.89 \pm 11.82$ \\
"Below" & $54.8 \pm 7.3$ & $78.9 \pm 9.9$ & $8.334 \pm 0.838$ & 1.78 & $45.99 \pm 16.85^{*}$ \\
"Control" & $59.6 \pm 3.1$ & $79.1 \pm 10.0$ & $9.068 \pm 0.825$ & 2.16 & $92.84 \pm 4.47^{*}$ \\
$p$ values $(F$ ratio) & $0.579(0.599)$ & $0.375(1.161)$ & $0.119(3.101)$ & - & $0.009(11.02)$ \\
\hline
\end{tabular}

The control group had no nighttime lighting. (mean $\pm \mathrm{SD}, n=3$ )

*Significantly different means within columns $(P<0.05)$ 


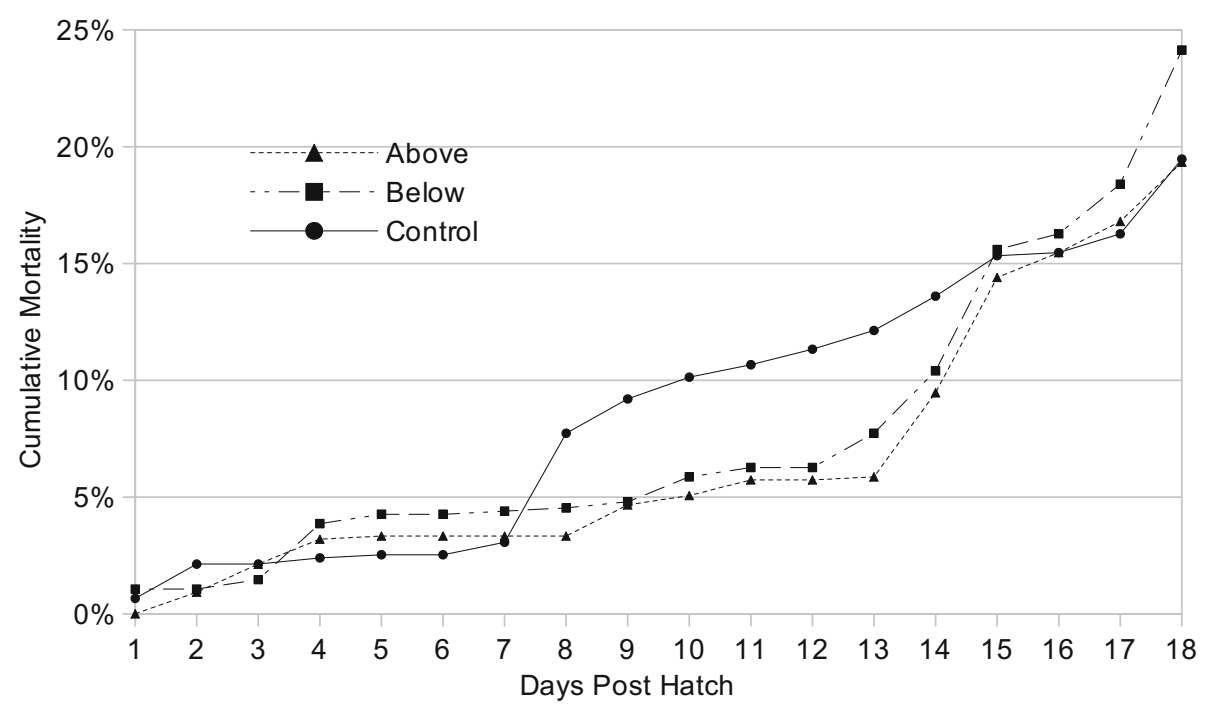

Fig. 1 Cumulative mortality of larval yellow perch under different low-level nighttime light treatments of different source locations (above and below the water's surface, the control had no nighttime light) over 18 days after hatching

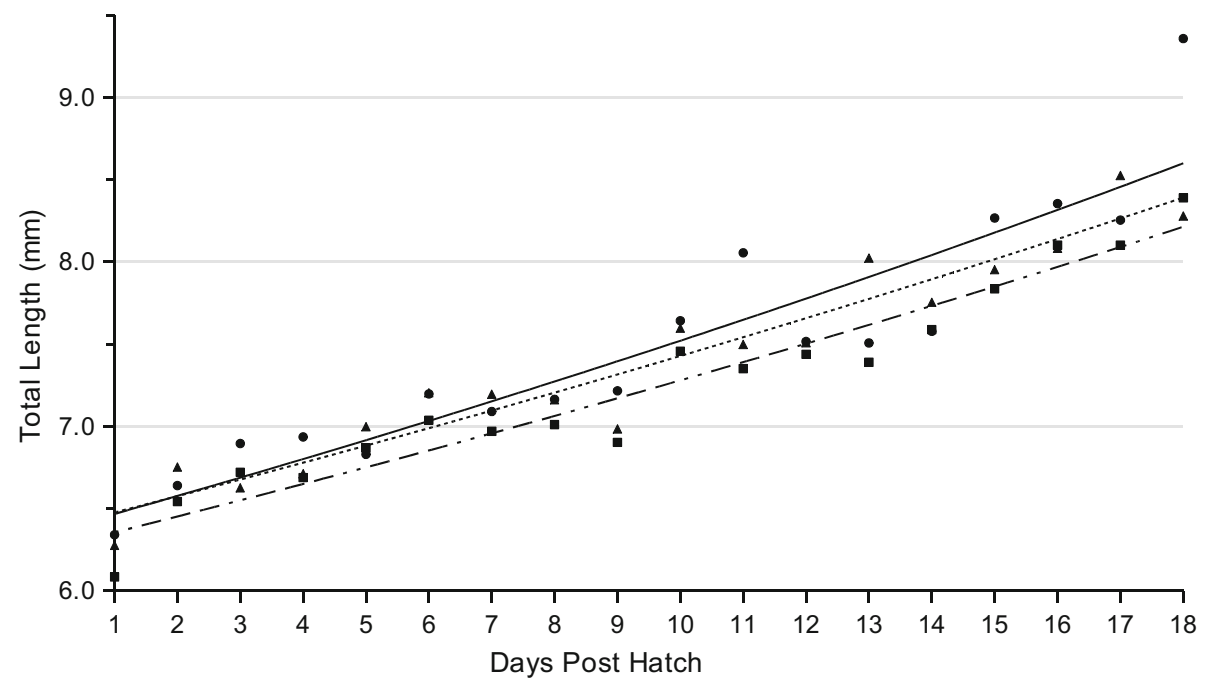

Fig. 2 Mean total length of five larval yellow perch (Perca flavescens) sampled daily over 18 days post hatching from different low-level nighttime light treatments of different source locations (above and below the water's surface, the control had no nighttime light). Exponential regression lines are fitted to the data. ANCOVA revealed no significant effect of the treatments on the length of larvae after controlling for time, $F_{2,265}=0.457, p=0.634$

"Below" treatments, respectively (Table 1). ANOVA indicated a significant difference $\left(F_{2,6}=11.02\right.$, $p<0.01$ ) of SBI success proportions between the "Control" and the "Below" treatments (Fig. 4).

Time of first inflation

When sampling fish daily, the first sighting of successful SBI occurred $10 \mathrm{dph}$ in the "Control" treatment where two of the five sampled fish had inflated their swim bladders. This occurred 2 days before any SBI was seen in either of the treatments with low-level, nighttime illumination. The "Above" treatment showed the first inflation $12 \mathrm{dph}$ and the "Below" treatment showed the first inflation $15 \mathrm{dph}$. 

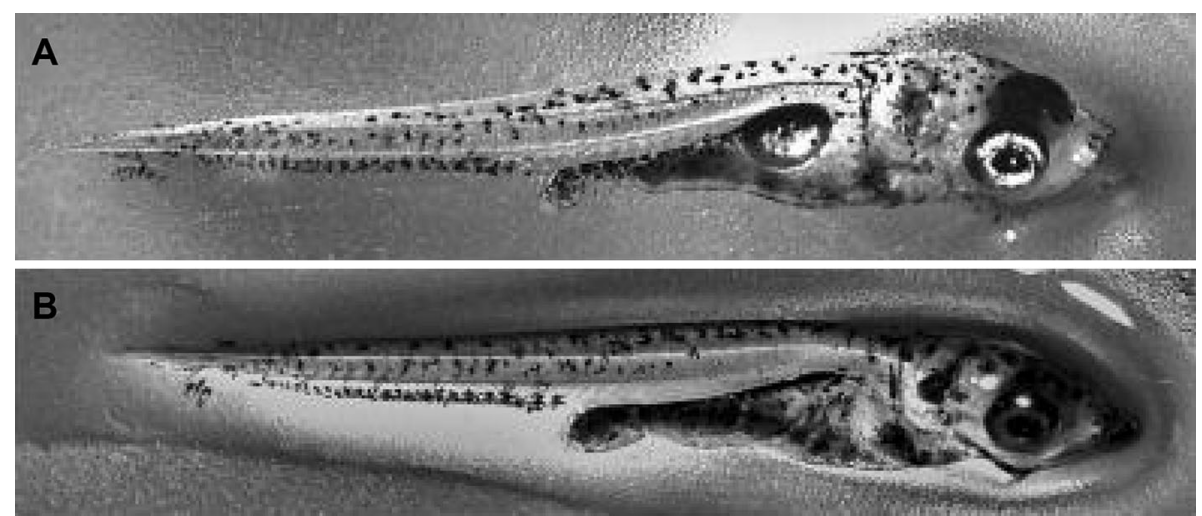

Fig. 3 Images of larval yellow perch (Perca flavescens) 11 dph showing successful (a) and unsuccessful (b) first swim bladder inflation. In a the swim bladder can be seen to be inflated via the presence of a large bubble just above the gut while this feature is absent in b

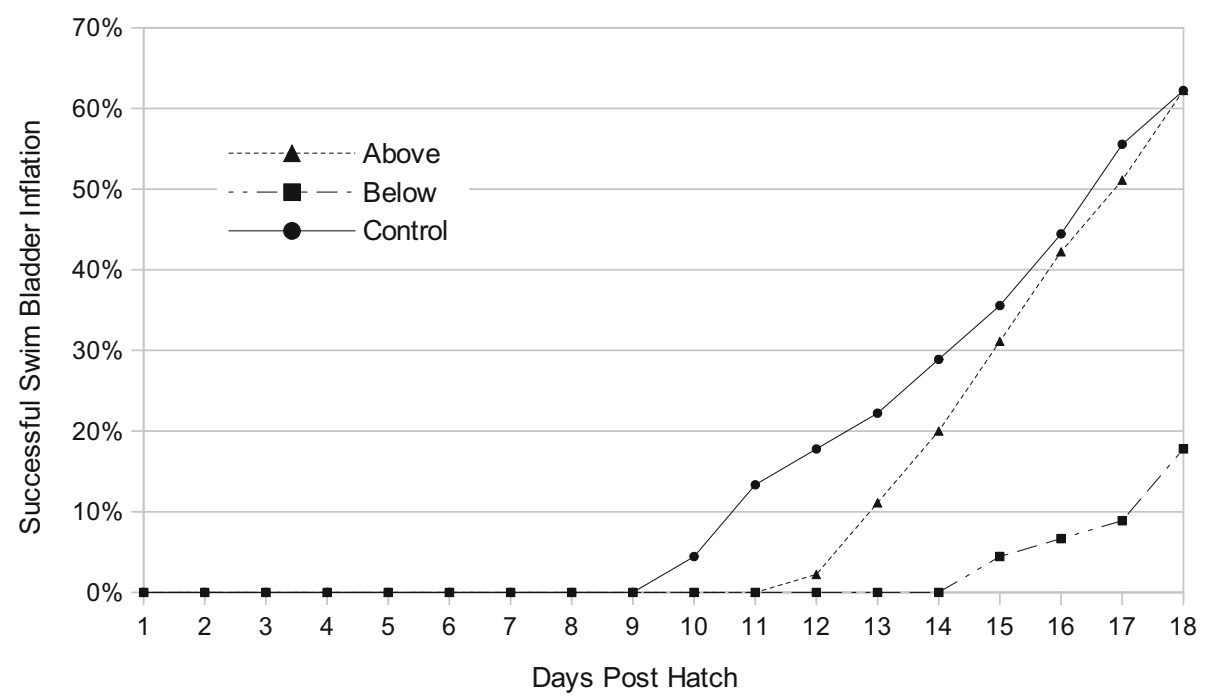

Fig. 4 Cumulative percent of daily sampled larval yellow perch (Perca flavescens) with successfully inflated swim bladders from different low-level nighttime light treatments of different source locations (above and below the water's surface, the control had no nighttime light) over 18 days post hatching

\section{Discussion}

The control treatment, with no nighttime illumination, exhibited the greatest proportion of successful SBI, and therefore we reject our hypothesis that wild larval yellow perch rely on their phototactic response to locate the water's surface and inflate their swim bladders during the night. However, our results suggest that the photopositive behavior of the larvae contributed to the resulting patterns of survival and SBI. The significant difference in inflation proportions between the "Control" and "Below" treatments is likely due to the phototactic behavior toward light at the bottom of the tanks, preventing access to air, leaving them unable to successfully inflate their swim bladders. This idea is corroborated by the lack of a significant difference between inflation proportions in the "Above" and "Control" treatments. We believe that this study, along with the successful use of light traps to catch larval perch (Manci 1983), provides evidence that larval perch are photopositive at least up until $19 \mathrm{dph}$, and most likely longer.

It does not appear that yellow perch rely on this phototactic response to assist them in initially inflating their swim bladders, as it would be expected that the proportion of inflation in the "Above" group would be significantly higher than in the "Control" and "Below" groups, which was not the case. This is consistent with 
the literature on the performance of yellow perch with failed SBI, suggesting that failed SBI does not directly lead to mortality, but leads to a decrease in overall performance, which, in many environments, may result in mortality (Czesny et al. 2005; Jacquemond 2004).

The role of phototaxis in reducing SBI relates with previous studies on the effect of tank colors on larval performance (Cobcroft et al. 2012; Downing and Litvak 1999; Jentoft et al. 2006; Tamazouzt et al. 2000). Perch have shown increased rates of inflation in black and gray tanks, as opposed to white tanks. This improvement has been attributed to the lack of incidental light reflecting off the tank's sides and bottom, better contrast when visually detecting food items, and reducing a behavior of fish clinging next to tank walls (Craig 2000; Hinshaw 1985).

Because the difference in inflation proportions was significant between the "Below" and "Control" treatments, and the only difference in lighting was during the evening hours, there is the possibility that a significant amount of initial SBI occurs at night. This would make sense ecologically, since swimming toward the surface to inflate leaves the larvae particularly susceptible to predation, which decreases at night (Milinski 1993).

The lag in the time in which first SBI was seen in treatments with nighttime light suggests that this illumination, even when very dim, plays a role in the suppression of the first SBI. These results are consistent with previous studies on extended photoperiod and SBI (Migaud et al. 2006; Tandler and Helps 1985; Trotter et al. 2003). These studies point to a compromise between periods of light and dark being needed for successful SBI to occur (Fielder et al. 2002). In contrast, Brüning et al. (2011) found that a 24 h photoperiod, as opposed to a $12 \mathrm{~h}$ light photoperiod, resulted in earlier SBI in the closely related Eurasian perch Perca fluviatilis, highlighting the need for species-specific research. Additionally, because these species occupy a wide latitudinal range with large differences in photoperiod, it is important to also consider population-scale differences (Stepien and Haponski 2015).

The fragile nature of yellow perch larvae during post-hatch development is reflected in the low observed survival, which never exceeded 66\%. Additionally, the amount of larvae unaccounted after collecting survivors, mortalities, and samples ranged from 19 to 79 fish. Cannibalism was observed in this study and has previously been observed in the wild, as well as in culture (Malison 1999; Tarby 1974). Numerous fish were observed with conspecifics sticking out of their mouths, and in some cases mortalities were recovered in this state with both fish dead. It is reported that cannibalism requires a large size difference, and the range in the size of survivors $(6.33-12.04 \mathrm{~mm})$ suggests that some of the observed instances of cannibalism during this study most likely impacted the number of recovered fish and differences in the final TL (Baras et al. 2003). It is important to note that the mean percent recovery and mean TL of survivors were not significantly different between treatments.

The high percentage (93.0\%) of fish to inflate in the "Control" group is particularly interesting. The way water conditions were managed (use of spray mist nozzles, oil-sorbent sponges, and meshed standpipes) plus the dark conditions at night seem to have created an environment that favors inflation success more than should be expected. A replicate in the "Control" treatment had an SBI success percentage of 96.6\% (140 of 145 surviving fish) which is considered exceptional. Many culture conditions may introduce unnatural nighttime illumination, and wild yellow perch hatch near shore where they may be subject to light pollution. While the impacts of these lights may seem negligible, it is shown here that even relatively dim light can result in a decrease in the fraction of fish with successful SBI.

In conclusion, these results provide experimental evidence that yellow perch larvae are positively phototactic under light of an intensity as low as $1 \mathrm{~lx}$ until at least $19 \mathrm{dph}$. It is possible that the larvae's phototactic behavior negatively affects SBI if the light is below the surface, and possibly if a significant amount of light is reflected off of the internal surfaces of culture tanks. Low-intensity nighttime illumination was not shown to improve successful SBI in yellow perch. Outside of the SBI problem, this research suggests that future efforts to improve yellow perch survival should focus on the first 2 weeks of life.

Acknowledgements The authors thank Frederick P. Binkowski and Jeffrey C. Nuese for securing fertilized yellow perch eggs from the UWM yellow perch genetic improvement program. We thank Stephen C. Binter for help in designing the experiments. This work was supported by the United States Department of Agriculture [Cooperative Agreements \#5090-31320-002-03S, \#5090-31320-002-01S], Wisconsin Sea Grant [Grant number 144 AAB3869], North Central Regional Aquaculture Center [grant \#2014-28500-25753], and the University of Wisconsin-Milwaukee Research Growth Initiative Project "Epigenetic Transgenerational Impacts of Great Lakes Chemicals of Concern". 


\section{Compliance with ethical standards}

Conflict of interest The authors have no conflict of interests to declare.

Open Access This article is distributed under the terms of the Creative Commons Attribution 4.0 International License (http:// creativecommons.org/licenses/by/4.0/), which permits unrestricted use, distribution, and reproduction in any medium, provided you give appropriate credit to the original author(s) and the source, provide a link to the Creative Commons license, and indicate if changes were made.

\section{References}

Baras E, Kestemont P, Mélard C (2003) Effect of stocking density on the dynamics of cannibalism in sibling larvae of Perca fluviatilis under controlled conditions. Aquaculture 219(1-4):241-255

Barrows FT, Kindschi GA, Zitzow RE (1993) Detecting swim bladder inflation in fingerling walleyes. Progress Fish Cultur 55(2):90-94

Brüning A, Hölker F, Wolter C (2011) Artificial light at night: implications for early life stages development in four temperate freshwater fish species. Aquat Sci 73(1):143-152

Clayton RD, Summerfelt RC (2010) Gas bladder inflation in walleye fry cultured in turbid water with and without a surface spray. N Am J Aquac 72(4):338-342

Cobcroft JM, Shu-Chien AC, Kuah M, Jaya-Ram A, Battaglene SC (2012) The effects of tank colour, live food enrichment and greenwater on the early onset of jaw malformation in striped trumpeter larvae. Aquaculture 356-357:61-72

Craig JF (2000) Percid fishes. In: Pitcher TJ (ed) Blackwell Science, Oxford

Czesny SJ, Graeb BD, Dettmers JM (2005) Ecological consequences of swim bladder noninflation for larval yellow perch. Trans Am Fish Soc 134:1011-1020

Downing G, Litvak M (1999) The effect of photoperiod, tank colour and light intensity on growth of larval haddock. Aquacult Int 7(6):369-382

Egloff M (1996) Failure of swim bladder inflation of perch, Perca fluviatilis L. found in natural populations. Aquat Sci 58(1):15-23

Francis JT, Robillard SR, Marsden JE (1996) Yellow perch management in lake michigan: a multi-jurisdictional challenge. Fisheries 21(2): 18-20

Fielder DS, Bardsley WJ, Allan GL, Pankhurst PM (2002) Effect of photoperiod on growth and survival of snapper Pagrus auratus larvae. Aquaculture 211:135-150. https://doi.org/10.1016/S0044-8486(02)00006-6

Hamza N, Ostaszewska T, Kestemont P (2015) Development and functionality of the digestive system in percid fishes early life stages. In: Kestemont P, Dabrowski K, Summerfelt RC (eds) Biology and culture of percid fishes: principles and practices. Springer, Dordrecht, pp 239-264

Hart SD, Garling DL, Malison JA (2006) Yellow perch (Perca flavescens) culture guide. Iowa State University, Ames

Hinshaw JM (1985) Effects of illumination and prey contrast on survival and growth of larval yellow perch Perca flavescens. Trans Am Fish Soc 114(4):540-545

Jacquemond F (2004) Separated breeding of perch fingerlings (Perca fluviatilis L.) with and without initial inflated swim bladder: comparison of swim bladder development, skeleton conformation and growth performances. Aquaculture 239:261-273

Jentoft S, Øxnevad S, Aastveit AH, Andersen Ø (2006) Effects of tank wall color and up-welling water flow on growth and survival of Eurasian perch larvae (Perca fluviatilis). J World Aquac Soc 37(3):313-317

Kamaszewski M, Ostaszewska T (2015) Development of the sense organs in percid fishes. In: Kestemont P, Dabrowski K, Summerfelt RC (eds) Biology and culture of percid fishes: principles and practices. Springer, Dordrecht, pp 227-237

Kestemont P, Mélard C, Held JA, Dabrowski K (2015) Culture methods of Eurasian perch and yellow perch early life stages. In: Kestemont P, Dabrowski K, Summerfelt RC (eds) Biology and culture of percid fishes: principles and practices. Springer, Dordrecht, pp 265-293

Kurata M, Ishibashi Y, Takii K, Kumai H, Miyashita S, Sawada Y (2014) Influence of initial swimbladder inflation failure on survival of Pacific bluefin tuna, Thunnus orientalis (Temminck and Schlegel) larvae. Aquac Res 45(5):882-892

Kyba C, Mohar A, Posch T (2017) How bright is moonlight? Astron Geophys 58(1):1.31-1.32

Malison JA (1999) A white paper on the status and needs of yellow perch aquaculture in the Northern Central Region. University of Wisconsin, Madison

Manci WE (1983) Harvesting photopositive juvenile fish from a pond using a lift net and light. Aquaculture 34(1-2):157-164

Marsden JE, Robillard SR (2004) Decline of yellow perch in Southwestern Lake Michigan, 1987-1997. N Am J Fish Manag 24:952-966

Migaud H, Wang N, Gardeur JN, Fontaine P (2006) Influence of photoperiod on reproductive performances in Eurasian perch Perca fluviatilis. Aquaculture 252(2):385-393

Milinski M (1993) Predation risk and feeding behavior. In: Behavior of teleost fishes, 2nd ed. Chapman and Hall, New York, pp 285-306

Partridge GJ, Benetti DD, Stieglitz JD, Hutapea J, McIntyre A, Chen B, Scholey VP (2011) The effect of a 24-hour photoperiod on the survival, growth and swim bladder inflation of pre-flexion yellowfin tuna (Thunnus albacares) larvae. Aquaculture 318(3-4):471-474

Peruzzi S, Westgaard JI, Chatain B (2007) Genetic investigation of swimbladder inflation anomalies in the European sea bass, Dicentrarchus labrax L. Aquaculture 265:102-108 
Prestinicola L, Boglione C, Cataudella S (2014) Relationship between uninflated swim bladder and skeletal anomalies in reared gilthead seabream (Sparus aurata). Aquaculture 432:462-469

Rekecki A, Meeus W, Chiers K, Adriaen J, Boyen F, Declercq A, Decostere A (2016) Swimbladder hyperinflation in burbot Lota L. larvae. Aquac Res 47(2):673-676

Stepien CA, Haponski AE (2015) Taxonomy, distribution, and evolution of percidae, ch 1. In: Kestemont P, Dabrowski K, Summerfelt R (eds) Biology and culture of percid Fishes. Springer, Dordrecht, pp 3-60. https://doi.org/10.1007/978-94-0177227-3_1

Tamazouzt L, Chatain P, Fontaine P (2000) Tank wall colour and light level affect growth and survival of Eurasian perch larvae (Perca fluviatilis L.). Aquaculture 182(1-2):85-90

Tandler A, Helps S (1985) The effects of photoperiod and water exchange rate on growth and survival of gilthead sea bream (Sparus aurata, Linnaeus; Sparidae) from hatching to metamorphosis in mass rearing systems. Aquaculture 48(1):71-82

Tarby MJ (1974) Characteristics of yellow perch cannibalism in Oneida Lake and the relation to first year survival. Trans Am Fish Soc 103(3):462-471

Trotter AJ, Battaglene S, Pankhurst P (2003) Effects of photoperiod and light intensity on initial swim bladder inflation, growth and post-inflation viability in cultured striped trumpeter (Latris lineata) larvae. Aquaculture 224(1):141-158

Trotter AJ, Pankhurst PM, Battaglene SC (2005) A finite interval of initial swimbladder inflation in Latris lineata revealed by sequential removal of water-surface films. J Fish Biol 67(3):730-741

Tsuji M, Uji S, Tsuchihashi Y, Okada K, Kawamura T, Katoh T, Sawada Y (2016) Promotion of initial swim bladder inflation and effect of initial inflation failure on skeletal malformation in cultured seven-band grouper Hyporthodus septemfasciatus (Thunberg). Aquac Res 47(6):1954-1971

Warton DI, Hui FKC (2011) The arcsine is asinine: the analysis of proportions in ecology. Ecology 92(1):3-10

Woolley LD, Qin JG (2010) Swimbladder inflation and its implication to the culture of marine finfish larvae. Rev Aquac 2(4):181-190

\section{Publisher's Note}

Springer Nature remains neutral with regard to jurisdictional claims in published maps and institutional affiliations. 